\title{
Changing Scenario of Health Problems due to HIV Infection
}

\author{
Laveena D’Mello ${ }^{1}$ \& Govindaraju B. M. $^{2}$ \\ ${ }^{1}$ Senior Lecturer, Social Work Department, Srinivas Institute of Management Studies, \\ Mangalore-575001, India \\ ${ }^{2}$ Asst. Professor, Dept. of Sociology, Mangalore University, Karnataka, India. \\ E-mail: lavynoronha@gmail.com
}

Type of the Paper: Medical Case Study.

Type of Review: Peer Reviewed.

Indexed In: OpenAIRE.

DOI: http://dx.doi.org/ 10.5281/zenodo.583295.

Google Scholar Citation: IJHSP

How to Cite this Paper:

D’Mello, Laveena., \& B. M., Govindaraju. (2017). Changing Scenario of Health Problems due to HIV Infection. International Journal of Health Sciences and Pharmacy (IJHSP), 1(1), 32-38. DOI: http://dx.doi.org/ 10.5281/zenodo.583295.

International Journal of Health Sciences and Pharmacy (IJHSP)

A Refereed International Journal of Srinivas University, India.

(C) With Authors.

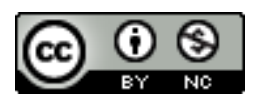

This work is licensed under a Creative Commons Attribution-Non Commercial 4.0 International License subject to proper citation to the publication source of the work.

Disclaimer: The scholarly papers as reviewed and published by the Srinivas Publications (S.P.), India are the views and opinions of their respective authors and are not the views or opinions of the SP. The SP disclaims of any harm or loss caused due to the published content to any party. 


\title{
Changing Scenario of Health Problems due to HIV Infection
}

\author{
Laveena D'Mello ${ }^{1}$ \& Govindaraju B. $M .^{2}$ \\ ${ }^{1}$ Senior Lecturer, Social Work Department, Srinivas Institute of Management Studies, \\ Mangalore-575001, India \\ ${ }^{2}$ Asst. Professor, Dept. of Sociology, Mangalore University, Karnataka, India. \\ E-mail: lavynoronha@gmail.com
}

\begin{abstract}
In Human Immunodeficiency Virus and Acquired Immuno-Deficiency Syndrome (HIV/AIDS) epidemic, today has become not only a public health issue but also one that is seriously affecting the dynamics of the social, cultural, economic and developmental pace of the society. India has a population of 1.2 billion people, around half of whom are adults in the sexually active age group. The first AIDS case in India was detected in 1986 and since then HIV infection has been reported in all states and union territories. Estimated number of people living with HIV/AIDS, 2009 People living with HIV/AIDS is 2.39 million. Adult (15 years or above) HIV prevalence is $0.31 \%$. Previously it was thought that around 5 million people were living with HIV in India - more than in any other country. Better data, including the results of a national household survey conducted in 2005-2006, led to a major revision of the prevalence estimate in July 2007. It is now thought that around 2.39 million people in India are living with HIV. Of these, an estimated 39\% are female and $4 \%$ are children. HIV prevalence in India may have declined slightly in recent years, though the epidemic is still growing in some regions and population groups. AIDS the killer diseases of the century is spreading with enormous rapidly and has now emerged as serious socio-economic and public health problems. The aim of the study is to find out changing scenario of Health Problems due to HIV infection. The objectives are to find out the socio-economic background of the respondents and to know the health issues of the positive people. The fifty samples 25 male and 25 female were selected from ART centre of Dakshina Kannada Districts at Karnataka State, India for this study.
\end{abstract}

Keywords: HIV/AIDS, People Living with HIV/AIDS (PLHA) Opportunistic Infections (OIs) and Antiretroviral (ARVs).

\section{INTRODUCTION :}

A few years ago AIDS was considered death sentence, today it is viewed as a chronic and deadliest infection that can be controlled. Human Immuno Virus (HIV) and acquired Immunodeficiency Syndrome (AIDS) are the most complex problems of 21st century. Aids were recognized as emerging diseases only in the 1989s and have rapidly spread to each and every age group of human life. South and south-Asia are now an epicentre of the HIV epidemics in all countries, India is estimated to have about $4.8 \mathrm{HIV}$ positive cases. Almost 30 years have passed since AIDS was first identified. Since then almost 14 million people have died from the disease and a further 33 million are believed to be living with HIV. Life expectancy in some countries in Africa has fallen by 20 years as a result of AIDS [1, 2]. In India four million people - almost one in a hundred adult-are HIV positives. The primary means of HIV transmission - sexual intercourse - has been known for over a decade, but that information does not prevent thousand of man and human, including boy and girls who have reached sexual maturity, from contracting the virus every day. Millions more are at risk from contaminated needles used to inject recreational drugs. Women have 
been targets of many HIV/AIDS many campaigns. This is partly following the example of family planning programmes that have targeted women in many countries, partly because it is relatively easy to reach large groups of women- pregnant women in antenatal clinics, for instance, or sex workers in red-light districts and partly because it was hoped that women could persuade their male sexual partners to be faithful use of condoms. Counseling can help a person to discuss their loss and to mourn appropriately. The family members may have unresolved fears about HIV infection for them and can be helped to come to decisions about HIV testing. The process of grieving may last many months, possibly even years, however, some people a single counseling session may be sufficient to clarify their thoughts and feeling, and to reassure them that they are coping as best as they can under the circumstances [1]. Other people may need several sessions, and some people never completely come to terms with a loss, particularly that of a child. The impact of the loss of life differs across families and communities, but one thing is clear: a child's life often falls apart when she or he loses a parent. More than 15 million children under 18 have lost one or both parents to AIDS. Caring for these children affected by HIV/AIDS, care for orphan's lies often with their extended families or communities [2].

\section{DATA ON HIV/AIDS :}

The spread of HIV in India has been uneven. Although much of India has a low rate of infection, certain places have been more affected than others. HIV epidemics are more severe in the southern half of the country and the far north-east. The highest estimated adult HIV prevalence is found in Manipur $(0.78 \%)$, followed by Andhra Pradesh (0.76\%), Karnataka (0.69\%) and Nagaland (0.66\%). In the southern states, HIV is primarily spread through heterosexual contact. Infections in the north-east are mainly found amongst injecting drug users (IDUs) and sex workers. Unless otherwise stated, the data on this page has been taken from a 2012 report by the Indian government's AIDS organization - NACO (National AIDS Control Organization). NACO releases HIV figures each year based on data gathered from HIV Sentinel Surveillance sites.
In 2010 surveillance was conducted at 1,359 sites and 358,797 samples were tested for HIV. The sites carry out tests among the highrisk groups and among antenatal clinic attendees [2]. Data gathered from the antenatal clinics are then used as a surrogate for the general population. Across India, HIV prevalence appears to be low among the general population, but disproportionately high among high-risk groups, such as IDUs, female sex workers, men who have sex with men (MSM) and STD clinic attendees. The average HIV prevalence among women attending antenatal clinics in India is $0.40 \%$. Much higher percentages are found among people attending STD clinics (3.6\%), female sex workers (2.67\%), injecting drug users (7.14\%) and men who have sex with men (4.43\%). Nearly two-thirds of HIV infections have been found in six of the country's 29 states the highest prevalence rates was found Mumbai, Karnataka, Nagpur, and Tamil Nadu, coastal Andhra and parts of Manipur and Nagaland.

In Karnataka, the prevalence among ANCs was 1.13 in 2001 and 1.75 percent in 2002. In 2001 there were four districts with an ANC prevalence of 2 percent or more, and these are located in the southern part of the state, in and around Bangalore, on the border with Tamil Nadu, or in northern Karnataka's “devadasi belt.” Devadasi women are a group of women, who historically, have been dedicated to the service of God. These days, this has evolved into sanctioned prostitution, as a result, many women from this part of the country are supplied to the sex trade in big cities such as Mumbai. Karnataka has a population 62.7 million and is a diverse state in the southwest of India. The Dakshina Kannada district has moved towards $0.25 \%$ prevalence which is half of state's estimated adult HIV prevalence. The positive cases have come down drastically by more than half from 2007 numbers. If the positive cases were about 1.245 in 2007 about 90 cases being reported per month including pregnant women, now the cases are averaging less 50 per month, as per Dr. Kishore Kumar M, District HIV/AIDS control officer. He pointed out that while in 2007 the test to positive ratio was $16 \%$ on 2013 it has come as to low as $1.45 \%$ delineating the statistic, "In 2007 of the 7,986 persons tested 1,245 were tested positive, in 2013 (till October end) of 
the 38, 985 tested only 567 were positive cases last year, as many as 38,294 went in for testing and there were 867 cases. This year, we expect the test number to reach 44,000 .

\section{METHODOLOGY :}

The aim of the study is to find out changing scenario of Health Problems due to HIV infection. The objectives are to find out the socio-economic background of the respondents and to know the health issues of the positive people [3]. The fifty samples 25 male and 25 female were selected from ART center of Dakshina Kannada Districts at Karnataka State, India for this study.

\section{DATA ANALYSIS: GENERAL BACK GROUND :}

Majority 50 percent of the respondents are in the age group between 36-45 years, 30 percent are 26-35 years, and 18 percent are 18-25 years and remaining 02 per cent respondent above 45 years. This is too early exposure to sex in the younger population; early marriages and this disease are found in the younger generation. 68 per cent respondents are belonging to Hindu Religion, 16 per cent respondents are Christian, and 16 percent are belonging to Muslim. And we can see that infection is not restricted to only one religion but we can find the infection in all the religion. Thus the infection HIV/AIDS will not have any discrimination based on age, gender, and religion. It effects equally to all. 62 per cent respondents are married, 22 percent respondents are unmarried, 14 percent of respondents are widows and remaining 2 percent of respondents are a widower. It is inferred from the data that Majority 62 per cent respondents are married and staying with their life partners. Both of them are positive and they are supporting each other with limitations. 56 percent of the respondents have completed just SSLC, more than one-third 36 percents have done their PUC education, 08 percent have completed their degree and above. Thus the majority of the respondents are educated up to SSLC. There is no difference between education backgrounds of the respondents. It is clear that education is also no bar in effecting the Virus. The majority of the respondents reside in the urban area. Here to HIV/AIDS will affect anyone who stays in the Rural or Urban area. 50 percent of the infected people live in a joint family, while 48 percent say in a nuclear family and a minimum of 2 percent stay in an extended family. The almost equal amount of frequency distribution in the data collected. The researcher can interpret that HIV infected are from both joint and Nuclear family [4].

\section{ECONOMIC BACKGROUND :}

$46 \%$ of the respondents are engaged in coolie work, $22 \%$ of the respondents are housewives $20 \%$ are Drivers, $10 \%$ are unemployed and $2 \%$ are govt employee. This reveals that majority of the respondents engaged in daily wages. There is also an equal number of distribution between various type of Jobs. So job too has no connection for infection. 48 percent are from an urban background, one third 44 percent are from rural and 8 percent of the respondents are from the semi-urban background. As per their monthly income is concerned, 48 percent of the respondent's monthly income is Rs. 3,001/- and above, 20 percent of the respondent's monthly income is from Rs.1, 501/- to Rs. 2,000/- and 16 percent of the respondent's monthly income is Rs. 2,001 to Rs. 3,000/-. And the 16 percent of the respondent's monthly income less than Rs.1, 500/-. Thus majority 48 percent of the respondent's monthly income is Rs. 3001 above. It is inferred from the data that HIV infection is effected to the lower middle-class family at large.

\section{SOCIAL BACKGROUND :}

The research study reveals that the relationship of the respondents with their relatives and neighbours is satisfactory. 54 percent of the respondents have a satisfactory relationship, 34 percent have a healthy relationship and 12 percent have a dissatisfactory relationship. It reveals they have accepted the HIV persons in the society. 56 percent are satisfied with their family, 26 percent are highly dissatisfied, and remaining 18 percent are very satisfied with their family life. Thus it is inferred that $74 \%$ of the respondents are satisfied with their family life and they have accepted the disease as it is. This may be possible because both the partners are infected with HIV 38 percent of them it affects mentally, for 36 percent expressed that they do not want support, and 26 percent needed the social and economic type of support. Thus for the majority of the 
respondents expressed that they need psychological support. The majority of them are supported by their life partners and they are support for each other to accept the diseases and another kind of difficulties in the life. 50 percent of the respondents are anxious about their children's future, 12 percent of respondents are not anxious about their children future because they are already married and settled in their life and the remaining 38 percent of them are do not have any children or single. Thus the majority of the respondents are anxious about their children's future. They are worried about their future that who will take care of them if they die soon, their health in case of positive children and education since the children are very young. 46 percent of the respondents do not feel that they are a burden for others, 34 percent respondents do feel and 20 percent of them sometimes feel that they are the burden on others. Thus majority 46 percent of the respondents feel that they are not burdened to others because they have accepted their positive status and they lead their life independently. Regarding the interest of HIV patients towards social activities, it is found that 58 percent of them had not lost their interest in social activities, 32 percent are sometimes losing their interest and the remaining 10 percent lost all hopes in involving themselves in social activities. Thus the majority of the respondents have continued taking interest in social activities. Regarding their attitude and self-confidence, 64 percent of the respondents reported positively and they involve themselves positively 36 percent of the respondents are of the opinion that they have lost their self-confidence. The majority have a positive attitude towards society and their approach due to environmental and societal support from the family members, relatives, and community at large. Regarding sharing about their problems with others, 40 percent of the respondents share only sometimes, 18 percent of them share their problems always with their friends and the remaining 42 percent of the respondents do not share their problems outside with anyone even with their relatives. Thus majority 58 percent of the respondents have made attempt in share their problems outside their family.

\section{HEALTH CONDITION :}

As far as health is concerned, 12 percent of the respondent's health condition is very good, 60 percent of the respondent's present health condition is good and 22 percent of them say bad and remaining 6 percent respondents said very bad condition. This indicates 72 percent of the respondent's present situation is good [11].This is due to Anti-Retroviral Therapy (ART) treatment, medical support available at Integrated Counselling and Testing Centre (ICTC) the nutritious food and rest taken by the respondents, the support received from the family and the positive living style of the people. 72 percent of the respondents taking medicines for their disease, 16 percent rarely get diseases so they meet Dr's rarely and remaining 12 percent do not have any effect and enjoy good health. It is clear that people are more cautious about their health and take care accordingly. Regarding their hospital visit, 42 percent of the respondents prefer to go government hospital, 34 percent respondent's visit the private clinic and 24 percent of the respondents go to PHC. HIVinfected peoples prefer to go Government hospital because of financial problems and free treatment available in the government hospital, especially ART. 48 percent of the respondents visit the once in a month to the hospital, 30 percent of the respondents are going to months, 14 percent of the respondents interacting six months once, and remaining 8 percent of the respondents not all. Thus majority 48 percent of the respondents will visit the hospital once in a month to the hospital. Regarding the satisfaction of Health; 60 percent of the respondents are satisfied with their health condition, 36 percent of the respondent's health condition is not so satisfied and 4 percent are not at all satisfied with their health condition. Thus the majority of the respondent's health condition is good. 42 percent respondents are going regularly to meet the counsellor at the testing centre. The 64 percent of the respondents are HIV symptomatic and remaining 36 percent of the respondents are asymptomatic. So the majority of the respondents are suffering from one or the other diseases which is due to HIV virus. Regarding their experience at the hospital; 52 percent of the respondents say that they get good support for treatment at the Hospital, 20 
percent people get only sometimes with the help of social worker, NGO worker, and the councillors support they get treatment in the hospital but 26 percent says they have very tough time to go for treatment in the hospital. Even a small fracture they will not get good treatment in any hospital. 86 percent of the respondents are on ART and remaining 14 percent of the respondents not yet started ART because they enjoy good health with high CD4 counts and they are asymptomatic. Regarding the cost per month for the medicine; 40 percent of the respondents spend Rs. 3,000/for their medical expenditure, 32 percent of the respondents spend Rs. 1,001/- to Rs.2, 000/and remaining 28 percent spend less than Rs. 1,000 -Thus it is clear that majority of the people spend their maximum part of income for their medical treatment which cannot be cut or reduce [8].

\section{SOCIO- ECONOMIC CONDITION :}

Eight percent of the respondents have very good relationship with their neighbours, 76 percent of the respondents have an average relationship and remaining 16 percent respondents have very poor and bad experience with their neighbours. As far as the Economic status of the respondents is concerned; 10 percent of the respondent's background is very good, 38 per cents background is satisfactory and remaining 52 per cent of the respondents are from the poor or very poor background. Thus those who are economically sound will get good treatment in the private hospital and the poor economic background people will suffer or struggle to get good treatment in government as well as the private hospital. 62 percent peoples living with them own house and remaining stay in rented house or with their relatives. 34 percent respondents get financial support with their family, 26 percent respondents receive help from NGO, 24 percent peoples get support from their relatives and remaining 16 percent respondents receive help from the government.

\section{CONCLUSIONS :}

AIDS is one of the greatest health challenges of this century, with hardly any medical care available in the country, the situation of the HIV-infected women in India is for worse than those in the western world where survival period has improved greatly for people who are diagnosed early and receive medical and other non-medical. However, the number of people spreading AIDS in smaller cities, towns, and rural areas is growing rapidly. Contributing problems are a lack of knowledge about where to get tested for HIV and the stigma surrounding the disease. For example, a study in Cambodia showed that only 16 percent of females ages 15 to 19 knew where to get tested. People are unlikely to abstain or practice safe sex if they do not know their HIV status. More women than men are at risk of contributing but not transmitting HIV because they are faithful to a partner who is not faithful to them. As an example: in Kigali, Rwanda, women with no other risk factor except their long-term partner from the largest proportion of women with HIV or AIDS. Young women's emotional involvement with their partners often prevents them from discussing sex or using condoms [4]. In this study, an attempt to discuss briefly the basic facts about AIDS personal, social and family concerns of the respondents. We hope readers will messages to their near and dear ones with an effort to prevent, control the further spread of this killer diseases and also helps in providing psychosocial support services to those to those HIV-infected individuals by HIV/AIDS trained counsellor.

\section{REFERENCES :}

[1] Gracious Thomas (1995). AIDS and Family Life Education. Rawat Publications, Jaipur and New Delhi.

[2] UNICEF (2004). Mapping India's Children. UNICEF in Action. United Nations Children's Fund, (UNICEF) New York, USA.

[3] D'Mello Laveena and Govindaraju, B.M. (2013). A Study on Socio-Economic condition of HIV Positive people in Dakshina Kannada. SDMIMD, Mysore, India, paper was published in the Conference Proceeding, ISBN Code 97881-922146-5-8.

[4] Nagendra Shilaja. (2008). AIDS in India, ABD Publishers, Jaipur, India,

[5] Chaudhry, Muhammad Anwar (2005). Level of Awareness about HIV/AIDS among Truck Drivers and their attitude 
towards Person with HIV AIDS. Journal of Medical Sciences, 3(1).

[6] Choopanya (2013). Antiretroviral prophyl axis for HIV infection in injecting drug users in Bangkok, Thailand (the Bangkok Tenofovir Study). A randomized, doubleblind, placebo-controlled phase 3 trial. Lancet, 381(9883): 2083-9200.

[7] Cohen, M. (2011). Prevention of HIV-1 Infection with early antiretroviral therapy. New England Journal of Medicine, 365: 493-505.

[8] D’Mello Laveena \& Govindaraju, B. M. (2014). Health of Urban Women with Respect of HIV Infection: A Case Study in Dakshina Kannada. National Conference on Change and its Contemporary Social Relevance at Srinivas Institute of Management Studies, ISBN No. 978-81-929306-1- 9.

[9] Edlin Gordon and Golanty Eric. (2010). Health and Wellness, Jones and Bartlett Publishers, London.

[10] Flemming D. T., Wasserheit I. N. (1999). Epidemiological synergy to public health policy and practice: the contribution of other sexually transmitted diseases to sexual transmission of HIV infection. Sex Transmission Infection. 75: 3 - 17.

[11] Goldman B. Marlene and Hatch C. Maureen. (2000). Women and Health, Academic press, New York.

[12] Gracious Thomas, Sinha. N. P. Thomas K. Johnson. (1997). AIDS Social Work and Law. Rawath publications, Jaipur and New Delhi. 